\title{
Indian Ancient Techniques and Psychotherapy: \\ A Need of Time to Merge
}

\author{
Thseen Nazir $^{1 *}$
}

\section{ABSTRACT}

India, the country with rich culture and history has also a strong hold in medicine and Ayurveda. The centuries old way of treating psychological problems was unique in itself but with time it went dormant. Those age old techniques such as yoga, meditation, music and Vipassana are being rediscovered and slowly western world also recognized their important and effectiveness. This paper tries to explain some of those techniques and their effectiveness while dealing with psychological problems and also tried to put a light on how these techniques can be utilized and merged together in psychotherapy.

Keywords: Yoga, meditation, music, Vipassna and Psychotherapy

Indian society has a rich profound heritage. A need has been emerged that psychotherapy in India ought to mull over this legacy and the general population's mind, to convey the goods it deliver. Mental wellbeing is seen as a positive property, enthusiastic parity, the capacity to carry on a full, adjusted and inventive life, and the adaptability to manage life's inescapable difficulties. The Indian society and theory has been special in its cultivating of otherworldly autonomy and development in the general population. A typical Indian is under the solid effect of which could be Vedas, Upanishads, Yoga, Buddhism and its different schools. Indian Philosophy and Indian Psychology research share a system and trust the human has huge potential covered up in its being. Indian Ancient Psychology research additionally has an unending exhibit of systems to raise human awareness. Indian believed is a fortune rich with mental ideas, which have not yet been completely investigated by therapists or in different fields of everyday life. Ancient Indian believed is a storage facility of rich mental bits of knowledge clarifying unequivocal and unpretentious subtleties of procedures and constructs, for example, psychological well-being, attention, feeling, emotions, perceptions, inspiration, discernment self and personality, psychopathology and its treatment. Uncovering the enormous capability of

\footnotetext{
${ }^{1}$ Dept of Counseling and Guidance, Ankara University, Turkey *Responding Author

(C) 2016, T Nazir; licensee IJIP. This is an Open Access Research distributed under the terms of the Creative Commons Attribution License (http://creativecommons.org/licenses/by/2.0), which permits unrestricted use, distribution, and reproduction in any Medium, provided the original work is properly cited.
} 
Indian Ancient Techniques and Psychotherapy: A Need of Time to Merge

Indian thought in connection to psychological science is one of the colossal difficulties for analysts in the twenty-first century.

\section{ANCIENT TECHNIQUES OF INDIA}

\section{Yoga}

Yoga is an around 5,000-year-old antiquated "science, workmanship, and reasoning" got from Ancient Indian society. The word yoga makes an interpretation of from Sanskrit to English as "'to yoke,' mirroring its motivation in joining the psyche and body in agreeable unwinding".

Yoga can be seen as reasoning and routine of association, as an individual adds to his/her feeling of relatedness to other individuals, different creatures, the earth, and the universe. An individual likewise builds up his/her feeling of association with him/herself through yoga, turning out to be more mindful of the connections between mind, body, breath, sentiments, recollections, encounters, wellbeing, and conditions of awareness. The procedures of yoga expect to reveal and highlight these associations. Yoga starts with the body and the breath, additionally builds up the psyche, mindfulness and fixation, and levels of awareness. Yoga practices are one approach to incorporate work with the body, the breath, feelings, considerations, interpersonal connections, self-acknowledgment, solid way of life decisions, and mindfulness (inwardly, physically, rationally, socially, and profoundly/existentially).

As indicated by Sage Patanjali, there are eight parts of yoga, alluded to as ashtanga yoga, which incorporate yama (social control), niyama (individual order), asana (postures), pranayama (regulation of the breath), pratyahara (withdrawal of senses), dharana (focus), dhyana (meditation) and Samadhi (condition of ecstasy). A general component of these practices is their ability of affecting an organized psycho-physiological reaction, which is the direct opposite of the anxiety reaction. This "unwinding reaction" comprises of a summed up lessening in both psychological and physical excitement as saw in the changed action of the hypothalamic pituitary pivot and the autonomic sensory system, Benson H. 1975. Bagchi and Wenger 1957, in their initial exemplary yoga research study composed, "...physiologically Yogic contemplation speaks to profound unwinding of the autonomic sensory system without laziness or rest and a sort of cerebral action without exceptionally quickened electrophysiological indication yet likely with pretty much obliviousness to some outside boosts for a short or long time."

Yoga can possibly impact the treatment of tension, sorrow, and comorbid nervousness and wretchedness. By tending to customers' physical bodies alongside considerations and feelings, the act of Yoga can limit this crevice in the middle of understanding and change. Yoga offers customers procedures that they can rehearse all alone and, in a generally brief time, outside of the connection of remedial sessions. This gives customers a more dynamic part in their recuperating procedure, lessening their reliance on the social insurance framework and expanding their shots of reduction. A developing assemblage of confirmation now underpins

(C) The International Journal of Indian Psychology, ISSN 2348-5396 (e)| ISSN: 2349-3429 (p) | 28 


\section{Indian Ancient Techniques and Psychotherapy: A Need of Time to Merge}

what Yoga advisors and teachers have long seen and experienced: Yoga is useful for physical issues like back agony, as well as for mental sicknesses, for example, uneasiness and sorrow. Yoga therapeutics offers people with weakening emotional instability, who have long been reliant on the medicinal services framework; instruments that can stir their own inborn limits for mending. Through the act of breath work, asana, and therapeutic Yoga, and through Yoga's attention on the present minute, individuals with emotional issue can figure out how to view their changes in tension and discouragement as passing, as opposed to perpetual, conditions of awareness. Seeing these conditions of distress as a major aspect of the changing landscape of their lives gives these people a feeling of opportunity, individual office, and parity.

\section{Meditation}

Meditation is preparing for the psyche, to offer it some assistance with developing the qualities and aptitudes it needs to take care of its issues. Generally as there are a wide range of solutions for the different sicknesses of the body, there are a wide range of sorts of contemplation for the different issues of the psyche. The Meditation strategy is an ability went for tackling the brain's most essential issue: the anxiety and enduring it brings on itself through its own musings and activities. Despite the fact that the brain needs joy, regardless it figures out how to measure itself down with mental torment. Actually, that torment originates from the brain's misinformed endeavors to discover satisfaction. Contemplation reveals the purposes behind why the psyche does this and, in uncovering them, helps you to cure them. In curing them, it opens you to the likelihood of honest to goodness bliss, a joy you can depend on, a satisfaction that will never show signs of change or let you down.

Meditation offers a pathway to quiet mindfulness and essentialness by utilizing consideration adapt ably. There are both particular and nonspecific advantages. Meditation is a period for sitting discreetly, apparently dormant. From the peaceful minute's vacancy, the reflective state rises. Exploration proposes that contemplation can enhance an assortment of mental and psychosomatic issue, particularly those in which stretch plays a causal or entangling part. For instance, cardiovascular disarranges receptive to Transcendental Meditation incorporate hypertension and hypercholesterolemia (Schneider et al., 2005). Other medicinal conditions receptive to reflection incorporate asthma and stammering, and in addition hormonal scatters, for example, sort 2 diabetes, essential dysmenorrheal, and premenstrual disorder (now called premenstrual dysphonic issue) (Murphy and Donovan, 1997). Contemplation has likewise demonstrated compelling in improving insusceptible capacity in tumor patients, diminishing side effects of trouble in fibromyalgia and disease patients, and diminishing agony in different ceaseless torment disorders (Carlson, Speca, Patel, and Goodey, 2003; Davidson et al., 2003; Kabat-Zinn, 2003; Weissbecker et al., 2002; Williams, Kolar, Reger, and Pearson, 2001). Reflection might likewise upgrade medications for psoriasis, prostate tumor, and atherosclerosis (Kabat-Zinn, 2003).A emotional finding that unmistakably warrants replication was enhanced 


\section{Indian Ancient Techniques and Psychotherapy: A Need of Time to Merge}

mental working and decreased mortality among people in a nursing home who were taught Transcendental Meditation (C. Alexander, Langer, Newman, Chandler, and Davies, 1989).

Couple of scientists have analyzed reflection's unique reason as a self-completion procedure to improve qualities, for example, astuteness and sympathy. On the other hand, some spearheading studies give a significant establishment. Care seems to improve recognition as measured by perceptual affectability, handling velocity, sympathy, and synesthesia (Murphy and Donovan, 1997). A few sorts of reflection may enhance focus, response time, engine abilities, and field freedom (Andresen, 2000). In like manner, it is guaranteed that subjective execution is upgraded on measures of learning capacity, short-and long haul memory review, scholarly execution, execution on subscales of the Wechsler Adult Intelligence Scale, and a few measures of innovativeness (Cranson et al., 1991). In any case, for a basic survey that characteristics a significant part of the intellectual advantages guaranteed for Transcendental Meditation to hope and plan variables, see Canter and Ernst (2003). Identity variables are likewise altered. As anyone might expect, a few sorts of contemplation seem to decrease quality tension (Andresen, 2000). An investigation of the Big Five identity elements found that scruples was unaltered, yet the other four elements - extraversion, pleasantness, openness to experience, and particularly passionate dependability—all expanded (Travis, Arenander, and DuBois, 2004). Since contemplation is a self-regulation procedure, it is not astounding that specialists report sentiments of enhanced discretion and self-regard (Andresen, 2000). Given that few studies have found that members rehearsing contemplation had higher sympathy evaluations, it is likewise not shocking that measures of interpersonal working and conjugal fulfillment expanded. At long last, a few concentrates, most utilizing Transcendental Meditation, have proposed that contemplation might encourage development, in light of the fact that arbiters tend to score higher on measures of conscience, good and psychological improvement, self-completion, adapting aptitudes and resistances, and states and phases of cognizance (C. Alexander and Langer, 19.

\section{Vipassana}

The Pali expression "Vipassana" is a mix of two words "Vi" + 'passana'. "Vi" implies different and "passana" deciphers as right comprehension or care (sati) of one's attitude and physicality. The term Vipassana is additionally rendered as 'understanding', that is, knowledge into the three general qualities of presence: change, unacceptability and pitifulness. On the other hand, this practice is called Insight Meditation, which is gotten from the Pali name for this practice Vipassana Bhavana, which means the advancement of understanding. Vipassana is an old, free, nonprofessional, nonsectarian, moral, all inclusive, psychological science of other worldly improvement. It is based upon efficient, nonstop, target perception of oneself at the level of sensations. This exceptional type of perception catalyzes a multilevel, frameworks improvement all through the strata of one's identity. Some portion of Vipassana's one of a kind commitment to emotional well-being gets from its star grouping of mental activities. Vipassana can be 


\section{Indian Ancient Techniques and Psychotherapy: A Need of Time to Merge}

conceptualized as the creation through reflection of a power field that stimulates new examples in six levels of identity.

To start with Vipassana actuates changes at the sub-atomic level of the middle person's body. Precise, progressively refined and unobtrusive self-perception, without response, changes the stream of anxiety related chemicals. The act of composure as an intermittent and deep rooted center diminishes the recurrence and force with which substantial alert signs discharge their neurotransmitters. Capacity, discharge, sum and kind of flowing envoy neuro chemicals are modified by long haul routine of congruity and non-reactivity in the spot of annoyance, apprehension, or enthusiasm. The middle person's body to some degree will, after some time, come to comprise of distinctive substances than once in the past. Second Vipassana changes the science of the arbiter's body. As response examples change, as neuro-compound organization changes, and as a mindful and sympathetic way of life expands, rest, eating routine, and articulations of pain and also examples of joy may all be influenced. Psychosomatic illnesses, and essential capacities like weight, heart-rate, or readiness may be modified. Middle people end up maintaining a strategic distance from old propensities and developing new individual alternatives that spring from a quicker relationship to their bodies. On the off chance that over a lifetime you select a more quiet eating routine and more salubrious relaxations, you turn into an alternate creature. Our tissues have the ability to remold themselves to some degree because of our companionship with them. Attunement to our bodies is consequently experienced as nurturance of them. Thirdly Vipassana has a sensational impact at the mental level. Old buildings are surrendered, new states of mind and ethics are developed, recollections reemerge, connections are seen and created in new light, what's to come is deconstructed and revived in new ways, mankind's history and group are known not distinctive possibilities than was once accepted, and a great many events throughout one's life is re-experienced and rethought in another point of view. This is the most emotional and clear commitment of contemplation and the reason it is appealing to numerous individuals. Fifth, Vipassana is quality based instruction. The objective of Vipassana is to show the temperances of affection, empathy, happiness and serenity, and as a brain research it can be comprehended as joining direct learning. Prudence is developed in security, and it is additionally interposed from the samples of educators, who might live as cores of motivation in the brains of their understudies. In this sense, Vipassana fuses a subjective behavioral brain science that empowers dynamic routine of perfect methods for tackling issues, of interfacing with others, or of partaking in the public arena. Vipassana is preparing in mental society. What's more, finally Sixth Vipassana is an ecological brain science that hassles the criticism circle of agreement. The way we treat the world decides a significant part of the reaction that we will get. This rule is not constrained to the human world. As our internal world conveys what needs be through activities, the film of our surroundings vibrates

with the annihilation or delight that we have created. To the middle person, everything around us is a mirror in which we are uncovered. Everything around us is additionally feeling the sting of 


\section{Indian Ancient Techniques and Psychotherapy: A Need of Time to Merge}

our fierceness, or murmuring our murmur. Familiarity with our living surroundings is the mental sensibility of Vipassana.

\section{Music Therapy}

Man has long thought about the capacity of music to quiet, wheedle and restore individuals. In any case, it is just as of late that science has started to comprehend study and report the impacts of music in philosophy, which practically rules out uncertainty. Seen generally, music as treatment is both antiquated and youthful; its roots profound and its branches steadily developing. The advancement of music treatment as a calling has been in procedure since the force of music as a method of expression was first experienced. This force lies in its inalienable nature and its coinciding with human sentiments, feelings, and conditions of being. The rishis or holy people of old India and the Vedas initially archived the impacts of music on the individual and all life, it was left toward the western world to design the more current ideas of recuperating through music. There are presently genuine music treatment courses on the planet's best colleges and gainful openings abroad for music specialists. Music treatment is a unique sort of treatment where types of musical cooperation and correspondence are utilized close by verbal correspondence. Music Therapy is a set up medicinal services calling that uses music to address physical, enthusiastic, psychological, and social needs of people of all ages. Orderly procedure of mediation wherein the advisor offers the customer to advance wellbeing, some assistance with using music encounters and the connections creating through them as dynamic strengths of progress.

The antiquated arrangement of Nada Yoga, has completely recognized the effect of music on body and psyche and put into practice the vibrations radiating from sounds to elevate one's level of consciousness. By fortifying the states of mind and controlling the cerebrum wave designs, ragas could act as a corresponding medicine. According to an old Indian text, Swara Sastra, the seventy-two melakarta ragas (Raga is a succession of chose notes ) control the 72 vital nerves in the body.It is trusted that if one sings with due dedication, sticking to the raga lakshana (standards) and sruti shuddhi, (pitch immaculateness) the raga could influence the specific nerve in the body in an ideal way.

Amid the eighteenth century, researchers started to inquire about and study the impacts of music on the human body. It was not until the end of the nineteenth century that music was concentrated methodically. Connections in the middle of music and physiological or mental reactions were being highlighted. The relationship in the middle of music and feeling turned into a hotly debated issue for lab investigates. On the other hand, the improvement of music treatment is accepted to be a drop out of the wars. World War II prompted the improvement of vast scale screening procedures, bunch treatment, and expanded utilization of music in doctor's facilities (Tyson, F. 1981). It was amid that time, that artists started to work in doctor's facility settings straightforwardly with the patients and music treatment as a calling appeared. Research has 
demonstrated that music profoundly affects your body and mind (Elizabeth Scott, 2011).There are some of impacts of music on human body which are as follows:

Music with a solid beat can fortify brainwaves to reverberate in a state of harmony with the beat, with speedier beats bringing more honed fixation and more ready considering, and a slower rhythm advancing a quiet, reflective state. The adjustment in brainwave action levels that music can bring can likewise empower the cerebrum to move speeds all the more effectively all alone as required, which implies that music can convey enduring advantages to your perspective, even after you've quit tuning in. With adjustments in brainwaves, changes in other real capacities happen. Those represented by the autonomic sensory system, for example, breathing and heart rate can likewise be adjusted by the progressions music can bring. This can mean slower breathing, slower heart rate, and an actuation of the unwinding reaction, in addition to other things. This is the reason music and music treatment can check or keep the harming impacts of unending anxiety, significantly advancing unwinding, as well as be accustomed to bring a more positive perspective, keeping misery and tension under control. This can keep the anxiety reaction from wreaking ruin on the body, and can keep innovativeness and hopefulness levels higher, bringing numerous different advantages.

By playing recordings of unwinding music each morning and evening, individuals with hypertension can prepare themselves to bring down their circulatory strain - and keep it low. As per exploration reported at the American Society of Hypertension meeting in New Orleans, listening to only 30 minutes of established, Celtic or raga music consistently might fundamentally diminish hypertension (Teng et al., 2007). Music is useful for heart. Research demonstrates that it is musical rhythm, as opposed to style. Bernardi et al., (2006) enlisted young fellows and ladies, half of whom were prepared performers. The members slipped on earphones and listened to six styles of music, including rap and established pieces, with irregular twominute delays. As the members kicked back and tuned in, the scientists checked their breathing, heart rates and circulatory strain. The members had speedier heart and breathing rates when they listened to exuberant music. At the point when the musical impeded, so did their heart and breathing rates. Amid the musical delays, heart and breathing rates standardized or came to more ideal levels. Regardless of whether a man preferred the style of music did not make a difference. The rhythm, or pace, of the music had the best impact on relaxation. A day by day measurements of one's most loved pop tunes, established music or jazz can speed recuperation from incapacitating strokes. At the point when stroke patients listened to music for several hours every day, verbal memory and capacity to focus enhanced fundamentally contrasted with patients who got no musical incitement, or who listened just to stories read so everyone can hear (Sarkamo et al., 2008).Music can support the invulnerable capacity. Researchers clarify that a specific sort of music can make a positive and significant passionate experience, which prompts discharge of safe boosting hormones (Kuhn, 2002). This adds to a diminishment in the variables in charge of ailment. Listening to music or singing can likewise diminish levels of anxiety related hormone 


\section{Indian Ancient Techniques and Psychotherapy: A Need of Time to Merge}

cortisol. More elevated amounts of cortisol can prompt a diminished safe reaction (Le Roux, et al., 2007). The thought that music makes us more intelligent got extensive consideration from researchers and the media. Music has the ability to improve a few sorts of higher mind capacity, for example, perusing and education aptitudes (Besson, et al., 2007), spatial-transient thinking (Jausovec, Jausovec, Gerlic, 2006) and numerical capacities (Schmithorst, Holland., 2004). Indeed, even kids with consideration shortage/hyperactivity issue advantage in arithmetic tests from listening to music heretofore. Prior it has been felt that listening to traditional music, especially Mozart, upgrades execution on intellectual tests. On the other hand, late discoveries of Schellenberg, Hallam, (2005) demonstrate that listening to any music that is actually agreeable effectsly affects cognizance.

\section{CONCLUSION}

In November 2009, the APA Monitor published an article on yoga as a practice tool for psychologists. Richard Gertz, of Alliant International University, explained in the article that "Psychologists have painted themselves in the corner by only doing talk therapy. There's much more that can be accomplished if you integrate it with other sorts of modalities, such as biofeedback, relaxation training or yoga." In the same vein, a 2012 article on integrating complementary and alternative medicine into the practice of psychology in Professional Psychology: Research and Practice, specifically discussed yoga as a complementary technique that psychologists can ethically integrate into their work.

There are numerous Ancient Indian techniques which had utilized for treating individuals who experiences diverse issues from many centuries yet these methods was torpid and dormat till the medieval periods. The scientific researchers had not been done enough on these techniques in order to bring these techniques out of dark ages. Be that as it May, the looks into and new logical scientists had put light on these procedures and appeared their significance and approve their adequacy. Every one of these systems had opened another part in psychotherapy for treating individuals adequately and effectively. Mostly there had been tremendous drive in Europe and America who made scientific studies on these ancient techniques and came out with wonders in healing humans. Now the time has came to incorporate these time old but tested and wonderful techniques with psychotherapy to cure humans. From the Ancient times, Indian believed are exceptionally commonsense and can be connected to day by day life and making life more rich and serene. These considerations and ideas might change one's mentality while performing the obligations, figuring out how to keep up a condition of passionate steadiness being in the materialistic world. This methodology is exceptionally applicable in the present fast and stressful life. At last I might want to conclude; at this crossroads it exceedingly expected to rediscover ethics of the Indian psychology research in light of the fact that it is still all that much crucial for individual and otherworldly development of each person. 
Indian Ancient Techniques and Psychotherapy: A Need of Time to Merge

\section{Acknowledgments}

The author appreciates all those who participated in the study and helped to facilitate the research process.

\section{Conflict of Interests}

The author declared no conflict of interests.

\section{REFERENCES}

Aftanas, L. \& Golosheykn, S. 2005. Impact of regular meditation practice on EEG activity at rest and during evoked negative emotions. International Journal of Neuroscience. 115, 6. 893-909.

Andresen, J. (2000). Meditation meets behavioral medicine. Journal of Consciousness Studies, 7 , 17-74.

Bagchi BK, Wenger (1957) MA. Electro-physiological correlates of some Yogi exercises. Electroencephalogr Clin Neurophysiol; Suppl. 7: 132-149.

Benson H. The Relaxation Response . New York, NY: Morrow; 1975.

Bernardi, L., Porta, C., Sleight, P. (2006). Cardiovascular, cerebrovascular, and respiratory changes induced by different types of music in musicians and non-musicians: the importance of silence. Heart, 92(4), 445-52.

Bernatzky, G., Bernatzky, P., Hesse, H.P., Staffen, W., Ladurner, G. (2004). Stimulating music increases motor coordination in patients afflicted with Morbus Parkinson. Neurosci Lett, 6, 361(1-3), 4-8.

Besson, M., Schon, D., Moreno, S., Santos, A., Magne, C. (2007). Influence of musical expertise and musical training on pitch processing in music and language. Restor Neurol Neurosci., 2, 5(3-4), 399-410.

Canter, P., \& Ernst, E. (2003). The cumulative effects of Transcendental Meditation on cognitive function: A systematic review of randomized controlled trials. Wiener Klinische Wochenschrift, 115, 758-766.

Carlson, L. E., Speca, M., Patel, K. D., \& Goodey, E. (2003). Mindfulness- based stress reduction in relation to quality of life, mood, symptoms of stress and immune parameters in breast and prostate cancer outpatients. Psychosomatic Medicine, 65, 572-581.

Cranson, Alexander, (1991). Transcendental meditation and improved performance on intelligence-related measures: A longitudinal study. Personality and Individual Differences, 12, 1105-1116.

Davidson, R. J., \& Harrington, A. (Eds.). (2002). Visions of compassion. New York: Oxford University Press.

Davis, Daphne M. \& Hayes, Jeffrey, A. (2011). What are the benefits of mindfulness? A practice review of psychotherapy-related research. Psychotherapy. 48(2) 198-208.

Elizabeth Scott, M.S. (2011). Music and Your Body: How Music Affects Us and Why Music Therapy Promotes Health How and Why Is Music A Good Tool For Health?, Retrived from About.com Guide, October 27, 2011. 


\section{Indian Ancient Techniques and Psychotherapy: A Need of Time to Merge}

Green, E. E., Green, A.M., \& Walters, E.D. (1970). Voluntary control of internal states: Psychological and physiological. Journal of Transpersonal Psychology. 2, 1, 1- 26.

Harmat, L., Taka'cs, J., Bo'dizs, R. (2008). Music improves sleep quality in students. J Adv Nurs., 62(3), 327-35.

Jing, L., Xudong, W. (2008). Evaluation on the effects of relaxing music on the recovery from aerobic exercise-induced fatigue. J Sports Med Phys Fitness, 48(1), 102-6.

Kabat-Zinn, J. (2003). Mindfulness-based interventions in context: Past, present, and future. Clinical Psychology: Science and Practice, 10, 144-156.

Kabat-Zinn, Jon. (1991). Full catastrophe living: using the wisdom of your body and mind to face stress, pain, and illness. Delta Trade Paperbacks.

Khalfa, S., Bella, S.D., Roy, M., Peretz, I., Lupien, S.J. (2003). Effects of relaxing music on salivary cortisol level after psychological stress. Ann N Y Acad Sci., 999, 374-6.

Kuhn, D. (2002). The effects of active and passive participation in musical activity on the immune system as measured by salivary immunoglobulin A (SIgA).J Music Therapy.39(1), 309.

Ladenberger-Leo E. (1986). Effect of music on the general feeling of persons performing monotonous work. Med Pr, 37(6), 347-52.

Le Roux, F.H., Bouic, P.J., Bester, M.M. (2007). The effect of Bach's magnificat on emotions, immune, and endocrine parameters during physiotherapy treatment of patients with infectious lung conditions. J Music Ther., 44(2), 156-68.

Murphy, M., \& Donovan, S. (1997). The physical and psychological effects of meditation (2nd ed.). Petaluma, CA: Institute of Noetic Sciences.

Newberg, A.B. \& Iversen, J. 2005. The neural basis of the complex mental task of meditation: Neurotransmitter and neurochemical considerations. Med. Hypotheses, 65, 3, 6256.

Oelkers-Ax R., Leins, A., Parzer, P., Hillecke, T., Bolay, H.V., Fischer, J., Bender, S., Hermanns, U., Resch, F. (2008). Butterbur root extract and music therapy in the prevention of childhood migraine: an explorative study. Eur J Pain, 12(3), 301-13.

Sarkamo, T., Tervaniemi, M., Laitinen, S., Forsblom, A., Soinila, S., Mikkonen, M., Autti, T., Silvennoinen, H.M., Erkkila, J., Laine, M., Peretz, I., Hietanen, M. (2008). Music listening enhances cognitive recovery and mood after middle cerebral artery stroke. Brain, 131(3), 866-76.

Schneider, R. H., Alexander, C. N., Staggers, F., Orme-Johnson, D. W., Rainforth, M., Salerno, W., et al. (2005). A randomized controlled trial of stress reduction in African Americans treated for hypertension for over one year. American Journal of Hypertension, 18, 88-98.

Seligman, M. E. P., Csikszentmihalyi, M. (2000). Positive psychology: An introduction. American Psychologist, 55, 5-14.

Shannahoff-Khalsa, D. 2006. Kundalini Yoga meditation: Techniques specific for psychiatric disorders, couples therapy, and personal growth. New York: W.W. Norton \& Company.

Siegel, D. 2007. The mindful brain. New York: W.W. Norton \& Company. 
Simpkins, C. A. \& Simpkins, A. M. (2009). Meditation for therapists and their clients. New York: W. W. Norton \& Company.

Simpson, S.D., \& Karageorghis, C.I. (2006). The effects of synchronous music on 400-m sprint performance. J Sports Sci., 24(10), 1095-102.

Teng, X.F, Wong, M.Y, Zhang, Y.T. (2007). The effect of music on hypertensive patients. Eng Med Biol Soc, 4649-51.

Travis, F., Arenander, A., \& DuBois, D. (2004). Psychological and physiological characteristics of a proposed object-referral/self-referral continuum of self awareness. Consciousness and Cognition, 13, 401- 420.

Weissbecker, I., Salmon, P., Studts, J. L., Floyd, A. R., Dedert, E. A., \& Sephton, E. (2002). Mindfulness-based stress reduction and sense of coherence among women with fibromyalgia. Journal of Clinical Psychology in Medical Settings, 9, 297-307.

Williams, A., Kolar, M. M., Reger, B. E., \& Pearson, J. C. (2001). Evaluation of a wellnessbased mindfulness stress reduction intervention: A controlled trial. American Journal of Health Promotion, 15, 422-432.

How to cite this article: T Nazir (2016), Indian Ancient Techniques and Psychotherapy: A Need of Time to Merge, International Journal of Indian Psychology, Volume 3, Issue 4, No. 63, ISSN 2348-5396 (e), ISSN: 2349-3429 (p), DIP: 18.01.098/20160304, ISBN: 978-1-365-32518-2 